\title{
AC 2010-1076: A FUEL CELL SYSTEMS COURSE FOR UNDERGRADUATE ENGINEERING STUDENTS
}

Patrick Cunningham, Rose-Hulman Institute of Technology 


\title{
A Fuel Cell Systems Course for Undergraduate Engineering Students
}

\begin{abstract}
A fuel cell course has been developed for junior/senior mechanical engineering students. The focus of the course is on systems level modeling of the fuel cell stack and the balance of plant. Lectures, assignments, and labs are geared toward introducing students to fuel cells and developing the basics of thermodynamics, electrochemistry, and other disciplines needed to explain fuel cell behavior. As components and subsystems are covered in the course students will build the corresponding sub-models. Emphasis is placed on deciding between alternative models or modeling approaches. Relevant technical papers are brought into the classroom to facilitate these discussions. This also serves to build student confidence in engaging current technical literature, critically analyzing the work, and making appropriate use of the results. By the end of the term students individually completed their own fuel cell models, which were suitable for dynamic performance prediction and control system development. Along the way, students gained valuable experience bringing together the often fractured topics of their engineering education into the single fuel cells application. While much of the course focused on the technical details of fuel cells, specific content was developed to address macro-issues affecting fuel cell technology and research. These societal, environmental, and economic factors were explored with grounding in technical knowledge. In this paper the formal course learning objectives, syllabus, assignments, and labs are presented. Examples of learning modules tied to each of the learning objective are given. The rationale for the course organization and content is also discussed and lists of lab equipment, references, and other resources are provided.
\end{abstract}

\section{Introduction}

Fuel cells have been a part of the space program since the 1950s and the NASA Gemini missions. However, they have only relatively recently entered the public consciousness amid discussions of reducing harmful emissions and reducing dependence on fossil fuels. Fuel cells show promise in both of these areas primarily as replacements to internal combustion engines, with a couple of important caveats. Proton exchange membrane (PEM) fuel cells will only produce water for emissions when they run on pure hydrogen and oxygen (or air). Other fuels are possible besides hydrogen, such as methanol, but result other emissions such as carbon dioxide. If using hydrogen fuel, the pure hydrogen must come from somewhere and the production process consumes a significant amount of energy. The only truly renewable source of hydrogen is electrolyzing water into hydrogen and oxygen using renewable energy such as wind or solar energy. Currently, most of the pure hydrogen produced comes from reforming natural gas, a fossil fuel source. ${ }^{1}$

If fuel cells are to replace some portion internal combustion engines as energy conversion devices, engineers will be needed to study, refine, and design them. Specifically, in automotive applications internal combustion engine powertrains have benefitted from more than 100 years of development, and consumers have grown accustomed to the performance, durability, and longevity the industry have achieved. Fuel cells must attain similar performance, durability, and 
longevity in order to be considered a reasonable substitute in consumers' eyes. Additionally, the cost of fuel cell powertrains must be comparable to internal combustion engine powertrains. As a result, fuel cell technology requires significant engineering development to meet these criteria and bring them to the mass market. Bringing fuel cells into the classroom will help motivate to pursue careers in the fuel cell industry and prepare them to be able to contribute to fuel cell development.

A relatively quick internet search will show that there are currently few fuel cell courses offered in higher education. There may be modules on fuel cells contained within other courses, for example within courses on thermodynamics, power plants, or renewable/alternative energy, but there are not many courses entirely devoted to fuel cells. Where such courses do exist they are usually at the graduate-level and are offered somewhat sporadically. For example, such graduatelevel fuel cell courses have been taught at, University of Connecticut, Penn State University, and Illinois Institute of Technology. This paper documents the first offering of a technical elective fuel cell course for junior and senior undergraduate engineering students. While it is open to all engineering majors with the proper background, the course is taught from within the mechanical engineering department.

This fuel cell course is focused primarily on PEM fuel cells and the development of systems level models of fuel cell stack operation. The course learning objectives, with emphasis added to the action verbs are:

After successful completion of this course, students will be able to:

1. Describe the components of a fuel cell and explain the purpose of each one.

2. Apply appropriate principles (e.g., Conservation of Energy, Conservation of Mass, etc.) to fuel cells to derive relevant model equations.

3. Develop and debug a nonlinear dynamic fuel cell simulation model in Matlab Simulink.

4. Explain and analyze dynamic fuel cell behavior.

5. Conduct repeatable fuel cell experiments and analyze experimental data to characterize fuel cell operation and performance.

6. Critically analyze the potential for fuel cells to improve efficiency and reduce pollution by assimilating social, economic, and technical factors.

Most of the course, specifically learning objectives 1-5, is geared toward the technical details, that is, the detailed theory, intuitive understanding, calculations, and practical operation of fuel cells. Learning objective 6 focuses on macro-details. That is, larger issues influencing fuel cell development. This content is absent from or awkwardly appended to typical engineering courses. This is not a typical engineering course. While there are derivations and calculations, there are also open-ended discussions, paper readings, and essay questions.

The learning objectives can be broadly connected together under the goal of helping to teach students the process of engineering through the practical application of fuel cells. From an instructor's vantage point the interconnections of material from different courses and domains of knowledge are obvious. Professors and researchers are comfortable with pulling the required 
information together from a wide range of sources. Practicing engineers with some experience are also adept at bringing the information they need together to analyze and understand the systems they work with. The interdisciplinary nature of fuel cells (involving thermodynamics, chemistry, electrochemistry, fluid dynamics, and heat transfer) naturally brings student's often fractured learning experiences in separate courses together to explain the operation of a single device. In this way, the overarching goal is to help students grow in their ability and comfort level in crossing the lines between disciplines and domains of knowledge - to learn this aspect of the process of doing engineering work - through studying fuel cells.

It is intended that, while this paper documents and shares what was done in this fuel cell course, it also fosters discussion of refinements and improvements. Certainly improvements can be made to the learning objectives and the assignments to better achieve the learning objectives. The remainder of the paper is organized to explain the course structure and content and to share details on specific assignments and learning modules.

\section{Course Structure and Content}

The fuel cell course has three 1-hour lecture periods per week and one 3-hour lab period per week to make a 4 credit-hour course. One lecture period per week is devoted to discussion of relevant papers, which serves to reinforce the technical content and facilitate discussion of the broader social, economic, and technical issues. The lab periods are used alternately for additional classroom instruction, experiments, recitation time, and modeling or project work. This adds a degree of flexibility to administering the course and provides the students with extra time to engage and reflect on what they are learning.

Student learning assessment is based on homework, experimental lab write-ups, a midterm exam, a nonlinear dynamic fuel cell model, and student projects. After the first half of the quarter students are evaluated on a midterm exam. This provides individual accountability over the theoretical foundations for the course. Questions on the midterm exam are both calculation based and concept based in the form of short essays. The second half of the quarter is evaluated based on student's individual work building a dynamic fuel cell model in Matlab Simulink and on the open-ended projects, which are conducted in teams. There is no final exam because the material becomes inherently more open-ended as the quarter progresses and the modeling and student project are better measures of this type of development.

There are a few and growing number of fuel cell textbooks available at this time. For this course Fuel Cell Fundamentals by O'Hayre, et al. ${ }^{2}$ has been selected as the required text. Other significant references used for this course include Fuel Cell Engines by Mench ${ }^{3}$, Fuel Cell Systems Explained by Larminie and Dicks ${ }^{3}$, Thermodynamics by Wark ${ }^{5}$ (Although, almost any thermodynamics text could serve as a reference, this is the one that was used.), and Fuel Cells From Fundamentals to Applications by Srinivasan 6 .

Rose-Hulman is on a 10 -week quarter schedule. The course calendar specifying the organization and topics for the term is included in Table 1 on the next page. 
Table 1 - Fuel Cell Course Calendar for 10-week Quarter

\begin{tabular}{|c|c|c|}
\hline Week & Topics & Reading \\
\hline 1 & $\begin{array}{l}\text { Introduction, Terminology, Fuel Cell Types, Open-Circuit Voltage } \\
\text { Lab - Open-Circuit Voltage from Gibb's Free Energy (Lesson) }\end{array}$ & $\begin{array}{l}\text { Chp. 1-2 } \\
\text { Paper } 1\end{array}$ \\
\hline 2 & $\begin{array}{l}\text { Open-Circuit Voltage (Temperature \& Concentration Effects) and } \\
\text { Calculations for Fuel Cell Experimentation } \\
\text { Lab } 1 \text { - Open-Circuit Voltage with Hardware and Software Introduction }\end{array}$ & $\begin{array}{l}\text { Chp. } 2 \\
\text { Paper } 1\end{array}$ \\
\hline 3 & $\begin{array}{l}\text { Fuel Cell Polarization Curves } \\
\text { Lab } 2 \text { - Polarization Curve with Concentration Effects }\end{array}$ & $\begin{array}{l}\text { Chp. 3-4 } \\
\text { Paper } 2\end{array}$ \\
\hline 4 & $\begin{array}{l}\text { Fuel Cell Polarization Curves - Continued } \\
\text { Lab } 3 \text { - Polarization Curve with Temperature \& Humidity Effects }\end{array}$ & $\begin{array}{l}\text { Chp. } 4-5 \\
\text { Paper } 3\end{array}$ \\
\hline 5 & $\begin{array}{l}\text { Dynamic Fuel Cell Modeling } \\
\text { Lab - Beginning Model Implementation, Simulink Review/Intro (Lesson) }\end{array}$ & $\begin{array}{l}\text { Chp. } 6 \\
\text { Paper } 3\end{array}$ \\
\hline 6 & $\begin{array}{l}\text { Balance of Plant Components and Modeling } \\
\text { Lab } 4 \text { - Fuel Cell Empirical Model }\end{array}$ & Chp. 10 \\
\hline 7 & $\begin{array}{l}\text { Environmental Impact of Fuel Cells } \\
\text { Lab - Model Implementation \& Project Work (Lesson) }\end{array}$ & Chp. 14 \\
\hline 8 & $\begin{array}{l}\text { Environmental Impact of Fuel Cells } \\
\text { Lab - Model Implementation \& Project Work (Lesson) }\end{array}$ & Chp. 7 \\
\hline 9 & $\begin{array}{l}\text { Model Implementation \& Project Work } \\
\text { Lab - Model Implementation \& Project Work (Lesson) }\end{array}$ & Chp. 9 \\
\hline 10 & $\begin{array}{l}\text { Student Project Presentations } \\
\text { Lab - Course Wrap-up \& Course Evaluations }\end{array}$ & \\
\hline
\end{tabular}

During week 1 the focus is on developing the motivation and context for talking about fuel cells, introducing the basics of fuel cell operation and terminology, and reviewing thermodynamics. During this first week the theoretical maximum open-circuit voltage equation based on Gibb's free energy is derived. Discussion of the first paper, by Pukrushpan, et al. ${ }^{7}$, also begins during the first week. It is on fuel cell systems-level modeling for control applications. The focus of this discussion is on where the modeling equations come from and what technical domains are involved. This helps to set the stage for the topics to be covered in subsequent weeks. This paper shows the application of the open-circuit voltage equation providing a reference point for the relevance of the material.

After setting the stage for the course in the first week, weeks 2-4 focus on modifying the opencircuit voltage equation to include temperature and concentration effects, arriving at the Nernst equation, and developing the theoretical framework for understanding fuel cell polarization curves. Specifically, the kinetic activation losses are developed through deriving the Bulter- 
Volmer equation and the simplified Tafel equation model. The ohmic losses due to charge transport are investigated by looking at the mechanisms of charge transport, in particular, ionic charge transport through the polymer electrolyte membrane. This also brings in the importance of membrane humidification for charge transport to occur and supporting empirical relations for conductivity. Then concentration losses at high current densities are discussed based on the local depletion of reactants at the respective electrodes due to diffusion limited mass transfer.

In week 2 the first experimental lab on open-circuit voltage is presented and relevant calculations for fuel cell experimentation and characterization are introduced, such as, relative humidity based on humidifier temperature set points and reactant utilization or stoichiometric ratio (based on Faraday's laws). In weeks 3 and 4, the laboratory experiments continue with focus on polarization curves, mirroring the theoretical content being presented in the lectures at this time. For example, the lab in week 4 investigates temperature and relative humidity effects on fuel cell polarization and includes finding the Tafel slope and exchange current density from the data.

The discussion of systems-level modeling, which was introduced during weeks 1 and 2 through the Pukrushpan, et al. paper ${ }^{7}$, deepens during weeks 5 and 6 . In the lab period during week 5 students begin building their nonlinear dynamic fuel cell models in Matlab Simulink with instructor guidance and direction. Specifically, students implement the portion of the model for the fuel cell stack voltage using operating conditions and reactant flows as inputs. Week 6 begins with presentations on the fuel cell balance of plant components, that is, the ancillary equipment needed to run a fuel cell stack. In this case, the balance of plant includes a compressor on the cathode air supply, humidifiers for both anode and cathode flows, mass flow controllers, and valves. There are variations in the balance of plant components based on the configuration and fuel cell type, but these are typical components for PEM hydrogen-oxygen fuel cells. Also during weeks 5 and 6 project selection and work begins. For their project, each student team will take over one class period and present material for their topic. The projects are intended to get students to do independent exploration following their specific interest in fuel cells. Students select project topics from an instructor provided list, which steps them beyond the material covered in class. Project topics can be focused on technical details or macro-level issues critically analyzed from a technical perspective.

Lifecycle analysis of fuel cells is used to investigate the environmental impacts of fuel cells during weeks 7 and 8. This is intentionally placed near the beginning of the project work so that students can build on and extend this analysis, if appropriate, in their projects. The lifecycle analysis also naturally ties into the larger issues surrounding fuel cells and brings these issues to the forefront of discussion once again.

During weeks 8 and 9 significant class time is set aside to work on the individual fuel cell model implementations and team projects. The model students are implementing from the Pukrushpan, et al. paper ${ }^{7}$ is relatively simple, but is by no means trivial to implement. Undergraduate engineering students likely have not encountered a model with such interconnections and complexity. By using class time to work on the models, the instructor can provide extra guidance on software specific details and spontaneous lectures to clear up common problems. In-class project work provided convenient time for students and the instructor to meet and go over their 
project outlines, flushing out details - clarifying expectations, providing focus, and solidifying topic direction.

The final week, week 10, is reserved for student project presentations. In effect, this represents a seminar series put on by the students. Presentations are assessed based on student's oral communication ability and content including how well they met their project objectives and how credible their analysis was.

Within the content and structure of the course it is also appropriate to present the grading scale based on the student assessments. Final course grades are based on a weighted average given by $20 \%$ - Homework \& Paper Discussion Participation + 20\% Midterm Exam + 20\% Laboratory Experiment Write-ups $+20 \%$ Fuel Cell Model in Matlab Simulink $+20 \%$ Project $=100 \%$.

\section{Assignments}

Assignments in this course include homework, paper reading and discussions, lab experiment write-ups, fuel cell model implementations in Matlab Simulink, and project presentations.

Homework assignments are given bi-weekly and cover calculations that students should be able to do, conceptual understanding based on the theoretical frameworks used to derive key equations, and questions summarizing aspects of the in-class discussion of the readings. Calculation problems may come directly from derived or empirical equations in the lectures or from the laboratory analyses. Conceptual questions are short essay or paragraph responses asking students to explain the physical meaning of theoretical equations or fundamental mechanisms discussed in class. Including questions from the paper discussions on the homework is intended to provide students with incentive to participate in the discussions by making is a part of their grade. It also gives two bases for evaluating students on the paper discussions: their reflects on what was discussed and their actual participation in the in-class discussions.

Three papers were selected for the in-class discussions including two technically oriented papers and one macro-level analysis papers. The Pukrushpan, et al. ${ }^{7}$ paper and a paper by Bao, et al. ${ }^{8}$ represent technical papers covering fuel cell systems-level modeling. Having more than one modeling paper provides the opportunity to compare and contrast modeling approaches. A paper on the efficiency and economics of fuel cells by Barbir and Gomez ${ }^{1}$ provides an example showing how technical analysis can inform macro-level decisions. It also opens the floor for critically analyzing such material, making sure students understand all the assumptions, tacit and explicit, that the author's make in their analysis.

The laboratory experiences are sequenced to be conducted at the same time that the corresponding theoretical material is presented in class. Lab 1 on open circuit voltage dependence on temperature and reactant concentration is paired with the development of the Nernst equation. This lab also introduced students to the hardware and software in the fuel cell lab. Lab 2 on polarization curves and their variation with concentration falls in sequence with the derivation of the Bultler-Volmer equation for reaction kinetics. Students are also introduced to stoichiometric ratio, reactant utilization, and test stand data files in this lab. Lab 3 continues with polarization curves, this time experimentally exploring temperature and humidity effects while 
Ohmic resistance and mass transport losses are being presented in the lecture periods. One part of the analysis in this lab had students finding the Tafel slope and exchange current density. Lab 4 has students fitting an empirical model to empirical polarization curves using a numerical solver while they are beginning work on their detailed nonlinear dynamic fuel cell models. For each lab assignment, students make theoretical predictions and compare them to experimental results. Write-ups are memos focused on presenting and discussing the results of the lab. Detailed calculations and resulting plots are attached to the memos as supporting documents. In this way, each lab experiment is designed to amplify the theoretical topics being covered in the concurrent class periods.

A Scribner $850 \mathrm{e} 100 \mathrm{~W}$ fuel cell test stand and $25 \mathrm{~cm}^{2}$ single-cell fuel cell form the heart of the fuel cell lab. The Scribner 850e unit includes instrumentation to independently control reactant flow rates, humidification, and backpressure. FuelCell ${ }^{\circledR}$ software, which accompanies the 850e unit provides a convenient interface for running polarization curve tests, current and voltage step responses, and even user defined test sequences. The single-cell fuel cell is instrumented with a heater in each end plate and a thermocouple so that the Scribner 850e unit can control the cell temperature. Several gases are used in support of the experiments. Primarily, dry Hydrogen, dry air (21\% Oxygen - 79\% Nitrogen), and dry Nitrogen are used. Hydrogen and air are the reactant gases and Nitrogen is used as a non-reactive purge gas. To vary the reactant concentrations two other Oxygen-Nitrogen mixtures were used, specifically, 10\% Oxygen - 90\% Nitrogen and 42\% Oxygen $-58 \%$ Nitrogen. This provides roughly half-concentration of Oxygen in air and twiceconcentration of Oxygen in air.

Students selected their projects from an instructor prepared list including:

1. Characterizing transient behavior of fuel cells during start up.

2. Comparing detailed life-cycle analysis between fuel cell hybrid, internal combustion engine hybrid, and conventional internal combustion engine vehicles.

3. Detailing manufacturing methods for bipolar plates or membranes and gas diffusion layers.

4. Computing the area of solar panels needed for electrolysis stations if all vehicles in a specified state were converted to Hydrogen fueled fuel cell vehicles - based on current solar panel technologies.

5. Explaining heat transfer and thermal management of fuel cell stacks.

6. Modifying the membrane hydration model in the Pukrushpan, et al. model $^{7}$ to incorporate the nonlinear variation of water content through the thickness of the membrane and quantifying the impact of this change.

This set of topics ranges from technically oriented material to macro-level material. For example, comparing life-cycle analyses engages the broader issue of fuel cell benefits and viability. The three projects selected by student teams were: characterizing fuel cell start up transients, computing the area of solar panels, and explaining heat transfer and thermal management in fuel cells. Each student team was responsible for developing and delivering a one class period lesson on their topic. As an intermediate assignment, students were required to complete a lesson plan and list of sources. After it was graded and returned, the lesson plan was used to foster an instructor-student discussion to refine and focus the project scope and direction. Student teams 
were evaluated based on four main dimensions in the presentation of their projects: clarity of presenting and completeness of addressing their project objectives, content and coherence, interactivity and questions posed to the class, and technical credibility.

Aside from the team projects, students were also required to individually implement a full nonlinear dynamic fuel cell model. This project, more than any other assignment, drew students into a deeper understanding of the processes and interconnections within a fuel cell system. The model students implemented came from the Pukrushpan, et al. paper ${ }^{7}$. It is a relatively simple fuel cell model, but is rather complex in its implementation. Other models in the literature are available, but this one was chosen for its relative simplicity and the completeness of its documentation. Students were, somewhat surprisingly, unaware of the availability of this model on the internet. The evidence was clear that they put in individual effort on their models. Two components of the model were provided to the students, the compressor map and the feedforward compressor motor controller. There was enough substance to the rest of the model that it would have distracted students from the larger goals of the modeling project if these had not been provided.

To help students build confidence in their abilities and interest in the subject, it was also important to support them to successful completion of their models. However, not all students submitted complete working models. From this experience there are a few suggestions to consider when assigning such a project. Formal discussions of modeling strategy, some software specific (here Matlab Simulink) and some just related to the component being modeled, were useful for helping students start the coding of the model. At several points throughout the class periods devoted to modeling software specific hints were provided to further support the students. In principle, it was desired to build each subsystem and test it independently before incorporating it into the full model. While work started out in this fashion it broke down as work progressed and students coded several subsystems without testing them. This complicated the tedious task of debugging a large interconnected model. Debugging was by far the most time consuming part of the modeling project. Students also needed assistance determining appropriate initial conditions for their models. As the final turn-in for their modeling project, students submitted their modeling files electronically and provided plots of its response to an instructor prescribed input. In this case the model input was a sequentially stepped input to the cell current and several internal variable and the stack voltage responses were plotted.

\section{Conclusions}

This course is intended to introduce students to technical aspects of fuel cells and the related issues in fuel cell development. It also contains specific instruction and assignments to challenge students to reflect on and apply their technical knowledge to the macro-level issues that influence fuel cell development. The learning objectives reflect this dual focus of technical detail and thoughtful analysis of broader impacts. Each assignment is designed with these objectives in mind, seeking to provide a coherent message to the students and assessment of where they stand on these measures. The interdisciplinary nature of fuel cells also provides a way of helping students to begin breaking down any barriers they have formed between domains of knowledge during their education. This paper shares one way to present a fuel cell course to undergraduate 
engineering students. It is hoped that this facilitates further discussion and refinement so that future engineers can be prepared to address the pressing energy challenges of our times.

\section{Bibliography}

1. Barbir, F. and Gomez, T., "Efficiency and Economics of Proton Exchange Membrane (PEM) Fuel Cells," International Journal of Hydrogen Energy, Vol. 22, 1997, pp. 1027-1037.

2. O'Hayre, Ryan, Cha, Suk-Won, Colella, Whitney, and Prinz, Fritz, Fuel Cell Fundamentals, Second Edition, Hoboken, NJ: John Wiley \& Sons, 2009.

3. Mench, Matthew, Fuel Cell Engines, Hoboken, NJ: John Wiley \& Sons, 2008.

4. Larminie, James and Dicks, Andrew, Fuel Cell Systems Explained, Second Edition, West Sussex, England: John Wiley \& Sons, 2003.

5. Wark, Kenneth, Thermodynamics, Fifth Edition, New York, NY: McGraw-Hill, 1988.

6. Srinivasan, Supramaniam, Fuel Cells - From Fundamentals to Applications, New York, NY: Springer, 2006.

7. Pukrushpan, Jay, Peng, Huei, and Stefanopoulou, Anna, "Control-Oriented Modeling and Analysis for Automotive Fuel Cell Systems,” ASME Journal of Dynamic Systems, Measurement, and Control, Vol. 126, 2004, pp. 14-25.

8. Bao, Cheng, Ouyang, Minggao, and Yi, Baolian, "Modeling and control of air stream and hydrogen flow with recirculation in a PEM fuel cell system - I. Control-oriented modeling," International Journal of Hydrogen Energy, Vol. 31, 2006, pp. 1879-1896. 